Revista Signos

2010 / 43

Número Especial

Monográfico $\mathrm{N}^{\circ} 1$

27-44

\title{
0 discurso relatado em textos de divulgação científica midiática constituídos pela relação de Solução
}

\author{
Janaína Becker \\ Maria Eduarda Giering \\ Universidade do Vale do Rio dos Sinos \\ Brasil
}

Resumo: Este trabalho relaciona-se ao projeto DCEROT (Divulgação Científica: Estratégias Retóricas e Organização Textual), vinculado ao PPG em Linguística Aplicada da UNISINOS, cujo objetivo é investigar a organização macroestrutural de textos de divulgação científica midiática publicados na versão on line de jornais e de revistas brasileiros e dirigidos a jovens. 0 modelo de análise dos textos, conforme sugere Bernárdez (1995), corresponde à Rhetorical Structure Theory (RST), de acordo com a qual há relações entre partes do texto consideradas núcleos e satélites. Dos 62 textos que constituem o corpus do projeto, 36 apresentam a relação de Solução, cujo núcleo apresenta uma resolução para o problema expresso no satélite. Este trabalho examina o discurso relatado nos textos constituídos pela relação de Solução. A análise revela que as ocorrências de discurso relatado fundamentam as asserções do produtor do texto, o qual visa a explicar questões referentes a determinadas áreas do conhecimento científico.

Palavras-Chave: Divulgação científica midiática, relação de Solução, discurso relatado.

Recibido: 20-XI-2009 Aceptado: 24-V-2010
Correspondencia: Janaína Becker (janainab@unisinos.br). Universidade do Vale do Rio dos Sinos. Avenida Unisinos 950, CEP 93022-000, São Leopoldo, Rio Grande do Sul, Brasil. 


\section{El discurso relatado en textos de divulgación científica mediática constituidos por la relación de Solución}

Resumen: Este trabajo se relaciona con el proyecto DCEROT (Divulgación Científica: Estrategias Retóricas y Organización Textual) vinculado al PPG en Lingüística Aplicada de UNISINOS, cuyo objetivo es investigar la organización macroestructural de textos de divulgación científica mediática publicados en versión on line de periódicos y de revistas brasileños y dirigidos a jóvenes. El modelo de análisis de los textos, conforme sugiere Bernárdez (1995), corresponde a la Rhetorical Structure Theory (RST), según la cual existen relaciones entre partes del texto consideradas núcleos y satélites. De los 62 textos que constituyen el corpus del proyecto, 36 presentan la relación de Solución, cuyo núcleo presenta una resolución para el problema expreso en el satélite. Este trabajo examina el discurso relatado en los textos constituidos por la relación de Solución. El análisis revela que las ocurrencias de discurso relatado fundamentan las aserciones del productor del texto, el cual tiene la finalidad de explicar cuestiones referentes a determinadas áreas del conocimiento científico.

Palabras Clave: Divulgación científica mediática, relación de Solución, discurso relatado.

\section{Reported speech in texts of scientific dissemination made up by solutionhood relation}

Abstract: This paper draws from DCEROT project (Portuguese acronym for Scientific Dissemination: Rhetorical Structure and Text Organization) -linked to UNISINOS Applied Linguistics Graduate Program- whose objective is to investigate the macrostructural organization of scientific dissemination of texts published in Brazilian newspapers and webzine oriented to young people. The text analysis model, as proposed by Bernárdez (1995), corresponds to Rhetorical Structure Theory (RST), according to which there are relations among texts' parts, labeled nuclei and satellites. Out of 62 texts that constitute this project's corpus, 36 present solutionhood relation, whose nucleus suggests the solution to a problem expressed within the satellite. This paper examines reported speech within texts constituted by solutionhood relations, and the analysis reveals that reported speech occurrences ground the assertions of the text producer, who aims at explaining issues about scientific knowledge-related areas.

Key Words: Texts of scientific dissemination, rhetorical relation solutionhood, reported speech.

\section{INTRODUÇÃO}

A divulgação científica corresponde a um ato de comunicação em que se transmitem os conhecimentos da ciência à sociedade em geral. Essencial à alfabetização científica, que equivale à compreensão mínima em ciência e em tecnologia necessária ao cidadão, a divulgação científica pode ocorrer na mídia impressa, mediante, por exemplo, jornais e revistas especializados em divulgação científica. 0 projeto DCEROT (Divulgação Científica: Estratégias Retóricas e Orga- 
nização Textual), coordenado pela Prof. Dr. Maria Eduarda Giering e vinculado ao Programa de Pós-Graduação em Linguística Aplicada da UNISINOS, examina a organização global de textos de divulgação científica dirigidos a jovens e publicados na versão on line das revistas Ciência Hoje das Crianças, Mundo Estranho e Recreio e do caderno Folhinha, do jornal Folha de São Paulo.

Adota-se como modelo de análise dos textos, como sugere o linguista textual Bernárdez (1995), a Rhetorical Structure Theory (RST), de acordo com a qual há relações entre partes do texto consideradas núcleos e satélites. Na etapa de análise quantitativa, verificam-se as relações RST que ligam os segmentos macroestruturais e estabelece-se o fim discursivo dos textos. Na etapa de análise qualitativa, a que se procede atualmente, analisam-se as relações mais recorrentes nos textos do corpus.

A relação de Solução é a terceira relação mais recorrente: dos 62 textos que integram o corpus, 36 são constituídos por essa relação. Considera-se a relação de Solução, em todas as suas ocorrências, da seguinte forma:

Núcleo: uma situação ou método/procedimento que traz, completa ou parcialmente, a satisfação da necessidade/desejo.

Satélite: um problema, uma questão ou um outro desejo expresso.

Condições no núcleo: não há.

Condições no satélite: apresenta um problema.

Condições na combinação núcleo + satélite: a situação apresentada no núcleo é uma solução (parcial) para o problema determinado no satélite.

Efeito: o leitor reconhece a situação apresentada no núcleo como uma solução (parcial) para o problema apresentado no satélite.

Locus do efeito: núcleo e satélite (Mann \& Thompson, 1988. Tradução do grupo de pesquisa DCEROT).

Assim, o núcleo da relação de Solução expressa uma situação, um método ou um procedimento que corresponde à satisfação ou à resolução de um problema, de uma questão ou de um desejo expresso no satélite. Conforme Becker e Giering (2008), nos textos de divulgação científica midiática do projeto DCEROT compostos pela relação de Solução, o satélite apresenta uma pergunta relacionada a áreas do conhecimento científico -astronomia, biologia, física, geologia, história, meteorologia e química- ao passo que o núcleo expressa a resposta a essa pergunta. Além disso, quanto às informações expressas pelo segmento equivalente ao núcleo da relação de Solução, os textos explicam as causas do problema, descrevem ações relacionadas à pergunta, apresentam as finalidades da questão ou relatam uma ação referente ao problema.

O objetivo deste trabalho é examinar o discurso relatado nos textos do corpus constituídos pela 
relação de Solução. De acordo com Charaudeau (1992, 2007, 2008), o discurso relatado corresponde a um procedimento linguístico mediante o qual um locutor relata a um interlocutor, em determinado espaço e em determinado tempo, as informações expressas por outro locutor a outro interlocutor em espaço e em tempo distintos. Quanto aos procedimentos de análise, este trabalho (i) verifica os segmentos macroestruturais do texto em que se insere o discurso relatado, (ii) reconhece o modo de denominação e as modalidades de enunciação dos locutores e a forma de relato do discurso de origem e (iii) relaciona o discurso relatado ao conteúdo do núcleo da relação de Solução.

\section{0 discurso relatado nos textos de divulgação científica midiática para jovens}

0 discurso relatado é um procedimento linguístico recorrente nos textos de divulgação científica midiática dirigidos aos jovens e constituídos pela relação de Solução. Dos 36 textos compostos por essa relação, 19 apresentam ocorrências de discurso relatado. Observe-se o seguinte texto:

Exemplo 1

(1) Como se forma a voz?

(2) 0 que faz uma pessoa ter voz diferente de outra?

(3) Basicamente, diferenças nas pregas vocais e no formato anatômico da região que vai da laringe à cavidade nasal. (4) A voz é uma das características mais exclusivas que a gente tem, tanto que até mesmo gêmeos idênticos possuem vozes distintas. (5) 0 som que fazemos para falar varia conforme movimentamos as pregas vocais. (6) Parecidas com duas cordas de violão, elas são capazes de produzir tons mais graves ou mais agudos de acordo com nossa vontade. (7) Mas é claro que essa variação tem um limite para cada pessoa, justamente por causa das diferenças anatômicas. (8) As mulheres, por exemplo, em geral têm a voz mais fina que a dos homens. (9) Normalmente, a laringe feminina é mais curta e a prega vocal naturalmente mais tensa, afirma o otorrinolaringologista Oswaldo Cruz, do Hospital Alemão Oswaldo Cruz, em São Paulo. (10) No infográfico abaixo a gente explica, passo a passo, como é o processo de formação da voz (Joly \& Bittencourt, 2008).

0 texto 'Como se forma a voz?' explica o motivo por que as pessoas possuem vozes diferentes. 0 segmento 2 desse texto, que equivale ao satélite da relação de Solução, expressa um problema relacionado à biologia: as diferenças entre as vozes das pessoas. Por sua vez, o núcleo da relação de Solução, que corresponde aos segmentos 3 a 9, apresenta a causa de as pessoas terem vozes distintas: 'as diferenças nas pregas vocais e no formato anatômico da região que vai da laringe à cavidade nasal'. Dessa forma, o núcleo da relação de Solução expressa a resolução do problema exposto no satélite mediante a apresentação de causas. A fim de exemplificar as 
diferenças anatômicas que determinam a distinção entre as vozes, os produtores do texto (Joly \& Bittencourt, 2008) apresentam, mediante o discurso relatado, uma afirmação de Oswaldo Cruz, especialista da área da biologia, à qual se relaciona, aliás, o conteúdo do texto.

0 discurso relatado equivale, conforme Charaudeau (2007), a um dito relatado (Dr) por um locutor-relator (Loc/r) a um interlocutor final (Interloc/r) em um espaço ( $\mathrm{Er}$ ) e em um tempo (Tr) diferentes daqueles (Eo-To) em que um locutor de origem (Loc/o) relatou a um interlocutor (Interloc/o) um dito (Do). 0 mecanismo do discurso relatado por ser representado pela Figura 1:

Eo/To

$\mathrm{Er} / \mathrm{Tr}$

$[\mathrm{Loc} / \mathrm{o} \rightarrow \mathrm{Do} \rightarrow$ Interloc/o $] \quad-\cdots \cdot-\cdot-\cdot-\cdot \rightarrow \quad[\mathrm{Loc} / \mathrm{r} \rightarrow \mathrm{Dr} \rightarrow$ Interloc/r $]$

Figura 1. Representação do discurso relatado (Charaudeau, 2007: 162).

O discurso relatado corresponde, consoante Charaudeau (2007), à integração, em um novo ato de enunciação, de um dito que passa a se subordinar ao locutor-relator. Esse processo, na verdade, evidencia que o dito relatado corresponde a um dito extraído de outro ato de enunciação, o que acarreta uma reificação do dito de origem, a qual serve para fundamentar a autenticidade do discurso do locutor-relator. Por isso, o discurso relatado corresponde a um discurso de prova.

No texto 'Como se forma a voz', a afirmação do otorrinolaringologista Oswaldo Cruz compara a laringe e a prega vocal femininas às masculinas. Sua declaração fundamenta a asserção dos produtores do texto de que as mulheres possuem a voz mais fina do que a dos homens, ou seja, sua afirmação constitui um discurso de prova.

Quanto aos segmentos em que se inserem as ocorrências de discurso relatado, conforme o Gráfico 1, dos 19 textos compostos pela relação de Solução que apresentam discurso relatado, em 12, o discurso relatado se insere nos segmentos da relação de Solução; em 7, nos segmentos da relação de Comentário; em 1, nos segmentos da relação de Circunstância; em 1, nos segmentos da relação de Elaboração; e, em 1, nos segmentos da relação de Preparação. Além disso, dentre os 19 textos, apenas dois apresentam ocorrências de discurso relatado em segmentos pertencentes a mais de uma relação. 


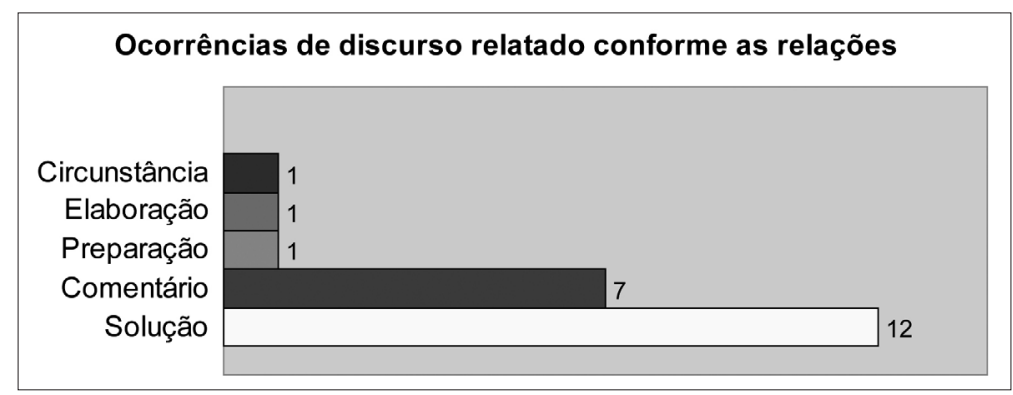

Gráfico 1. Ocorrências de discurso relatado conforme as relações.

Dessa forma, insere-se o discurso relatado, predominantemente, nos segmentos macroestruturais das relações de Solução e de Comentário. Leia-se o seguinte texto:

Exemplo 2

(1) Estrelas não caem!

(2) Entenda o que são os meteoros e como eles se desintegram ao entrar na atmosfera

(3) Quando morava em São Paulo e acordava cedo, bem de madrugada, lá pelas $5 \mathrm{~h} 30$, para correr um pouco sem o intuito de competir, eu reparava muitas vezes, quando olhava para o céu, que de repente uma estrela "caía". (4) E eu, todo contente, na hora fazia um pedido: na maioria das vezes, o meu desejo era ver outro desses objetos.

(5) Aí vinha-me uma pergunta: por que uma estrela cai? (6) 0 que são as "estrelas cadentes"? (7) Uma estrela que não agüentou seu peso e de repente caiu? (8) Ou será que Deus pegou uma estrela, pois estava sobrando no céu, e a "jogou"? (9) Ou talvez fosse um controle de população de estrelas, para não ficarem muitas por aí atrapalhando as constelações... (10) É só de vez em quando que vemos umas dessas cruzar o céu... (11) Mas será que são mesmo estrelas? (12) E o nosso Sol, será que um dia vai "cair"?

(13) Entre as órbitas de Marte e Júpiter, existem milhares de rochas de diverso tamanhos -- desde alguns centímetros a quilômetros de extensão. (14) Essas rochas fazem parte do Cinturão de Asteróides. (15) De vez em quando, algumas delas colidem entre si e seus pedaços são arremessados em direção à Terra. (16) Ou então alguma força gravitacional, provavelmente de Júpiter, o maior planeta do Sistema Solar, empurra uma dessas rochas em direção ao nosso planeta!

(17) Além disso, quando um cometa passa pela Terra, ao se aproximar do Sol, ele começa a perder parte do seu núcleo. (18) Devido ao intenso calor dessas erupções que acontecem em seu núcleo por causa do Sol, os cometas ejetam parte de seu material e deixam para trás um "tapete" extenso de pequenas pedras. (19) Quando a Terra cruza esse "tapete", vemos as chamadas chuvas de meteoros. 
(20) Quando essas pedras entram em contato com a nossa atmosfera, sua massa é queimada devido a sua alta velocidade de queda -- 71 quilômetros por segundo. (21) Causado pelo atrito das moléculas que constituem a camada de ar que envolve nosso planeta, esse processo é chamado pelos astrônomos de ablação. (22) E nós, aqui embaixo, vemos aquela "estrela" caindo. (23) Portanto, uma "estrela cadente" nada mais é do que um pedaço de pedra, às vezes do tamanho de um grão de arroz.

(24) Um meteoro é uma "estrela cadente" e, quando este é encontrado na Terra, recebe o nome de meteorito. (25) Algumas dessas rochas são bem grandes: o maior meteorito já visto no Brasil foi o Bendegó: descoberto na Bahia em 1784, ele pesava 5360 kg!

(26) Entendeu por que as estrelas cadentes não são estrelas? (27) Por isso, quando virmos uma "estrela cadente" riscar o céu, mostrando toda a sua beleza, acho bom desejarmos que uma outra dessas “caia” novamente! (Gonçalves, 2007).

0 texto ‘Estrelas não caem' explica o fenômeno da estrela cadente. Os segmentos 1 a 4 integram a relação de Preparação ${ }^{1}$, uma vez que visam a preparar o leitor mediante a antecipação do assunto do texto. Já os segmentos 5 a 12 correspondem ao satélite da relação de Solução, que expressa uma pergunta específica da área da astronomia: por que uma estrela cai? Os segmentos 13 a 25, por seu turno, equivalem ao núcleo da relação de Solução, uma vez que respondem à pergunta expressa no satélite mediante a descrição da passagem de pedaços de rochas do Cinturão de Asteróides ou de pedaços do núcleo de um cometa pela atmosfera da Terra. Finalmente, os segmentos 26 e 27 constituem o Comentário ${ }^{2}$, já que expressam uma apreciação do produtor do texto sobre um aspecto relacionado ao assunto: o pedido a ser feito quando se observa uma estrela cadente.

Localiza-se no núcleo da relação de Solução o segmento em que há uma ocorrência de discurso relatado: 'esse processo é chamado pelos astrônomos de ablação'. Nesse caso, o produtor do texto atribui aos astrônomos a autoria da designação de ablação ao processo de queima das pedras que entram em contato com a atmosfera da Terra. A descrição do processo de ablação equivale a um detalhamento da explicação do fenômeno da estrela cadente, o que justifica a ocorrência do discurso relatado em um segmento da relação de Solução. Em outras palavras, já que o texto 'Estrelas não caem' explica, nos segmentos da relação de Solução, o fenômeno da estrela cadente, a designação de um processo que integra esse fenômeno -a qual constitui o discurso relatado- também se insere nos segmentos da relação de Solução.

Dentre os 19 textos em que há ocorrências de discurso relatado, em 12, insere-se o discurso relatado nos segmentos que integram a relação de Solução, o que revela que esse procedimento linguístico localiza-se, predominantemente, nos segmentos dessa relação. Há, além disso, 7 textos em que o discurso relatado se situa nos segmentos do Comentário. Observe-se o seguinte texto: 


\section{Exemplo 3}

\section{(1) Existe alguma raça de cachorro que não late?}

(2) Sim! (3) Os cães da raça basenji emitem um monte de sons estranhos, de uivos a grunhidos, mas latir que é bom... (4) 0 motivo pra isso ainda é um mistério, mas uma das teorias é que, no Egito antigo - de onde ele seria originário - o basenji era usado como cão de caça. (5) Nessa função, quanto mais silencioso o cão fosse, mais eficiente ele seria para se aproximar das presas. (6) Daí para a espécie "desaprender" a latir, só foi necessário o processo evolutivo, no qual teriam predominado os indivíduos mais quietinhos. (7) Outra curiosidade estranha sobre a raça é sua mania de se lamber, como fazem os gatos... (8) Segundo a criadora Helena Coragem, dona do canil Baktaran, em Brasília, o basenji é um cachorro dócil e que adora crianças. (9) "Mas também é muito bagunceiro, principalmente quando ainda é jovem", diz Helena. (10) Outra característica da raça é a pelagem curta e as orelhas avantajadas e eretas, que dão ao cão uma permanente posição de "sentido!" (Vasconcelos \& Moreira, 2008).

0 texto 'Existe alguma raça de cachorro que não late?' explica por que os cães da raça basenji não latem. Nesse caso, o problema 'por que os cães da raça basenji não latem', que equivale ao conteúdo do segmento 3 e que se relaciona à área da biologia, é solucionado pela descrição da possível causa de esses cães não latirem, que corresponde ao uso desses cachorros como cães de caça no Egito e que integra os segmentos 4 a 7 . Os segmentos 3 a 7 constituem, portanto, a relação de Solução, em que o núcleo expressa uma resolução de um problema expresso no satélite. Por sua vez, os segmentos 7 a 10 expressam curiosidades sobre os cães da raça basenji: sua mania de se lamber, sua docilidade, sua afeição por crianças, sua disposição à bagunça, sua pelagem curta e suas orelhas avantajadas e eretas, o que integra a relação de Comentário do texto.

Dentre as informações expressas no Comentário, algumas são atribuídas a uma criadora e dona de canil, cuja voz não equivale à do produtor do texto, o que configura uma ocorrência de discurso relatado: "Segundo a criadora Helena Coragem, dona do canil Baktaran, em Brasília, o basenji é um cachorro dócil e que adora crianças. 'Mas também é muito bagunceiro, principalmente quando ainda é jovem', diz Helena”. A docilidade, a afeição por crianças e a predileção à bagunça dos cachorros da raça basenji são informações expressas não pelos produtores do texto (Vasconcelos \& Moreira, 2008) mas por uma especialista em comportamento canino -Helena Coragem. Assim, justifica a ocorrência do discurso relatado em segmentos da relação de Comentário o fato de as informações expressas mediante esse procedimento linguístico se relacionarem a curiosidades sobre os cães da raça basenji (conteúdo do Comentário), não à explicação do fato de esses animais não latirem (conteúdo da Solução).

A divulgação científica midiática equivale a uma troca de linguagem em que a instância de 
produção transmite à instância de recepção informações relacionadas à ciência. Os textos do corpus do projeto DCEROT constituídos pela relação de Solução, por exemplo, explicam determinados conhecimentos científicos ao leitor jovem não especializado. Consoante Charaudeau (2007), a instância de produção midiática possui a responsabilidade de obter, examinar e mostrar à instância de recepção a maior quantidade de informações possível, que são obtidas graças às fontes da informação.

Ao apresentar as fontes, a instância de produção deve nomeá-las mediante um modo de denominação e deve inseri-las no texto mediante uma modalidade de enunciação, que revelam a relação dessa instância com as fontes. 0 modo de denominação corresponde à identificação da fonte (a) pelo nome de uma pessoa ou de uma instituição, com ou sem marcas de deferência, de forma direta ou indireta, (b) pelo título de uma pessoa, que pode ser associado com o nome e com uma marca de deferência, (c) pela função, que se confunde, frequentemente, com o status e que aponta para a tecnicidade da fonte, e (d) por uma denominação vaga. A modalidade de enunciação, por sua vez, pode ser expressa por verbos cujo sentido revela, em maior ou em menor grau, a atitude da instância de produção quanto à fonte, como, por exemplo, os verbos ‘afirma', 'garante’ e ‘sugere’, e por locuções como ‘conforme’ e 'de acordo com'. Além disso, o relato do discurso de origem pode ser realizado das seguintes formas: (a) citação, mais ou menos integral, do dito de origem, mediante sua reprodução fiel; (b) integração parcial do enunciado de origem ao discurso do locutor-relator com alterações no dito de origem; (c) narrativização do dito de origem de forma que se integre totalmente ou que, inclusive, desapareça no dito relatado; (d) alusão ao dito de origem, que corresponde a uma evocação do que o locutor de origem afirmou ou costuma afirmar.

Observe-se o seguinte texto:

Exemplo 4

(1) Os continentes continuam se movimentando?

(2) Sim. (3) As placas tectônicas, que formam a superfície da Terra e sobre as quais estão os continentes e oceanos, se movem em média 10 centímetros por ano.

(4) "Para ter uma idéia, é a mesma velocidade com que nossas unhas crescem", afirma o geólogo Felipe Antonio Toledo, do Instituto Oceanográfico da USP. (5) Embora estejam sempre em movimento, as placas se deslocam com velocidades e direções diferentes. (6) Por isso, vivem em constante tensão, o que se manifesta através das erupções vulcânicas e dos terremotos. (7) 0 "motor" do deslocamento é o magma, uma mistura mineral incandescente com consistência de pasta de dente, que corre sob as placas. (8) 0 que garante que o magma fique em constante movimento é a diferença de temperatura que ele alcança de acordo com a proximidade do centro da Terra. (9) A porção mais próxima do centro aquece-se, sua densidade cai e ela sobe em direção à superfície. (10) Ao mes- 
mo tempo, a porção "fria" desce, formando um ciclo, que se repete há bilhões de anos. (11) Graças a ele, ao longo da história da Terra os continentes se juntaram -formando um megacontinente chamado Pangea-, se separaram e, de acordo com o que os geólogos já podem supor, estão se juntando novamente (Mizuta, 2008).

Duas ocorrências de discurso relatado integram este texto, que explica por que os continentes continuam se movimentando mediante a descrição desse deslocamento. A primeira ocorrência, em que a fonte da informação compara a velocidade de movimentação das placas tectônicas à de crescimento das unhas dos seres humanos, corresponde ao segmento 4: “'Para ter uma idéia, é a mesma velocidade com que nossas unhas crescem', afirma o geólogo Felipe Antonio Toledo, do Instituto Oceanográfico da USP”. Em relação ao modo de denominação, a fonte é identificada pelo título -'geólogo'- e pelo nome de uma pessoa -Felipe Antonio Toledo. Há, além disso, a indicação da instituição a que ela se vincula -Instituto Oceanográfico da USP. Quanto à modalidade de enunciação e à forma de relato do discurso de origem, o produtor do texto procede a uma citação, mediante a reprodução fiel do dito de origem, e emprega o verbo 'afirmar', uma das marcas linguísticas do discurso relatado, aliás, mais recorrentes nos textos constituídos pela relação de Solução.

A segunda ocorrência, que revela a suposição dos geólogos sobre a nova junção dos continentes, se localiza no segmento 11: “Graças a ele, ao longo da história da Terra os continentes se juntaram -formando um megacontinente chamado Pangea-, se separaram e, de acordo com o que os geólogos já podem supor, estão se juntando novamente”. Em relação ao modo de denominação da fonte da informação, expressa-se apenas sua função: 'geólogos'. Neste caso, ainda que não haja a designação da fonte mediante seu nome ou a instituição a que se vincula, sua função, que se relaciona à sua tecnicidade, garante sua credibilidade. Quanto à forma de relato do discurso de origem, integra-se o enunciado de origem ao texto mediante alterações. Além disso, quanto à modalidade de enunciação, emprega-se 'de acordo com', que, assim como 'segundo', equivale a um recurso linguístico de inserção dos discursos de origem nos textos constituídos pela relação de Solução.

Veja-se, ainda, o seguinte texto:

Exemplo 5

\section{(1) Brrrrr! 0 frio chegou}

(2) No dia 21 de junho, começa o inverno. (3) Do que você lembra quando pensa nesta estação? (4) "Em vestir muita roupa e comer comida diferente, como fondue", diz o garoto Luis Rafael Lassalle, 10. (5) Tem gente que se lembra de alguns pontos ruins do frio, como Gabrielle Castanheira da Silva, 8. (6) "É mais difícil para sair da cama e para tomar banho." 
(7) Mas uma coisa em que pouca gente pensa é o motivo de existir inverno. (8) Será que é porque a Terra fica mais longe do Sol? (9) Apesar de, por vezes, isso ocorrer, não é essa variação na distância que causa o frio maior. (10) Senão, como a gente explicaria que é inverno aqui no Brasil ao mesmo tempo em que é verão nos EUA e na Alemanha?

(11) As estações do ano estão relacionadas à quantidade de energia que a Terra recebe do Sol. (12) Como o Equador está inclinado em relação à estrela, em diferentes épocas do ano, partes diferentes da Terra são mais iluminadas do que outras, recebem mais energia e ficam mais quentes. (13) 0 frio é determinado também pela distância do local em relação ao Equador (quanto mais longe dele e mais perto dos pólos, mais frio faz) (Iwakura, 2007).

O texto 'Brrrrr! O frio chegou', que explica o motivo da existência do inverno, é constituído pelas relações de Preparação e de Solução. Os segmentos 1 a 6 integram a relação de Preparação, uma vez que instigam o leitor à leitura do texto mediante a citação de lembranças de crianças sobre o inverno após a indicação do início dessa estação do ano. Já a relação de Solução é constituída pelos segmentos 7 a 13, em que se descrevem as causas da existência do inverno: a quantidade de energia que a Terra recebe do Sol e a distância do local em relação ao Equador.

Na relação de Preparação, a fim de exemplificar lembranças de crianças em relação ao inverno, há duas ocorrências de discurso relatado, que se localizam nos segmentos 4 a 6: “"Em vestir muita roupa e comer comida diferente, como fondue', diz o garoto Luis Rafael Lassalle, 10. Tem gente que se lembra de alguns pontos ruins do frio, como Gabrielle Castanheira da Silva, 8. ‘É mais difícil para sair da cama e para tomar banho'”. As duas ocorrências de discurso relatado correspondem, quanto à forma, a citações, uma vez que o produtor do texto (Iwakura, 2007) reproduz, fielmente, o dito de origem. Apresentam, quanto à modalidade de enunciação, os verbos 'dizer' e 'lembrar-se': o primeiro, inclusive, corresponde a um recurso linguístico recorrente no discurso relatado dos textos constituídos pela relação de Solução. Quanto ao modo de denominação das fontes do discurso relatado, designam-se apenas seus nomes -Luis Rafael Lassalle e Gabrielle Castanheira da Silva.

A indicação de suas idades -10 e 8 respectivamente- revela que são crianças; portanto, não possuem uma função ou um título, cuja tecnicidade é dispensada devido à finalidade do relato: exemplificar lembranças de crianças sobre o inverno, o que, aliás, produz um efeito de aproximação com a instância de recepção dos textos -o leitor jovem.

Dos 62 textos de divulgação científica midiática do projeto DCEROT, 36 são constituídos pela relação de Solução. Quanto às informações expressas pelo núcleo dessa relação, Becker e Giering (2008) revelam que, em 17 textos, o núcleo apresenta as causas do problema expresso no 
satélite; em 13, o núcleo descreve uma ação referente ao questionamento exposto no satélite; em 5, o núcleo apresenta as finalidades da questão expressa no satélite; e, em 1, o núcleo relata um evento relacionado ao problema apresentado no satélite. Especificamente em relação ao discurso relatado, emprega-se esse procedimento linguístico nas quatro categorias de texto, conforme se observa no Gráfico 2, em que as barras amarelas representam a quantidade de textos em que há discurso relatado e as barras azuis se referem à quantidade de textos e às informações expressas pelo núcleo da relação de Solução.

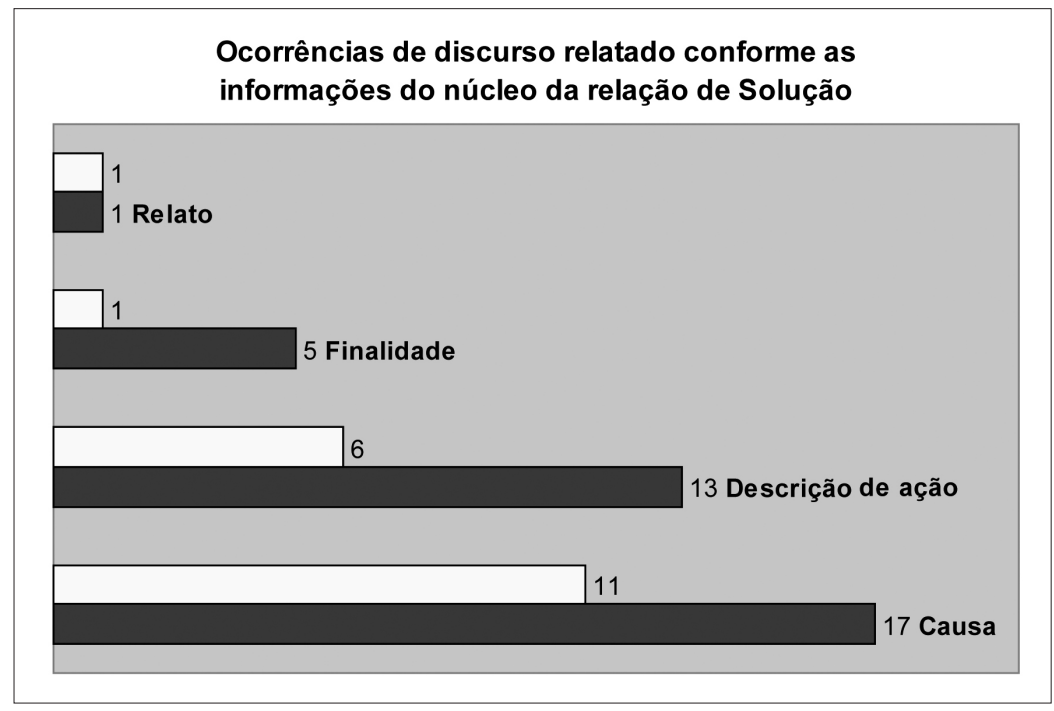

Gráfico 2. Ocorrências de discurso relatado conforme as informações do núcleo da relação de Solução.

Dessa forma, o discurso relatado se insere em 11 dos 17 textos cujo núcleo da relação de Solução expressa as causas do problema exposto no satélite, isto é, em aproximadamente $65 \%$ dos textos. Observe-se o seguinte texto:

Exemplo 6

(1) Trans... o quê?

(2) Entenda o que é a gordura de nome estranho que aparece nos rótulos das gostosuras!

(3) Você ganha um pacote de deliciosos biscoitos recheados com chocolate. (4) Antes 
de devorá-los, examina a embalagem. (5) Nela vem uma tabela dizendo que a gostosura tem um montão de calorias, vitaminas, proteínas e uns três tipos de gordura... (6) Ué, gordura não é tudo a mesma coisa? (7) Não. (8) É justamente por serem muito diferentes que, a partir de agosto, tornou-se obrigatório vir escrito no rótulo de todos os produtos a quantidade de cada uma delas.

(9) A gordura chamada trans é a principal vilã, apesar de ser a mais eficiente em deixar os alimentos mais crocantes, sequinhos, duráveis e apetitosos. (10) É justamente por isso que as indústrias gostam tanto de usá-la em seus produtos... (11) Portanto, é bem comum encontrá-la em grande quantidade nas delícias industrializadas, como sorvetes, batatas-fritas, pipocas, salgadinhos, biscoitos, bolos e principalmente na margarina. (12) Os animais ruminantes também produzem pequenas quantidades dessa gordura e, portanto, ela pode estar presente em certos alimentos como a carne e o leite de vaca.

(13) Toda gordura engorda , mas a trans é distinta das outras, pois era líquida e foi transformada em sólida e essa transformação é que a torna tão maléfica. (14) A nutricionista Vera Lucia Chiara, que estuda o assunto na Universidade do Estado do Rio de Janeiro (Uerj), contou à CHC On-line que essa gordura vai se acumulando em nosso corpo ao longo dos anos e pode causar doenças no coração e nas artérias.

(15) Chiara explica que as outras gorduras - que aparecem nos rótulos como as 'insaturadas' -a gente até precisa comer. (16) "Elas são essenciais porque participam de algumas funções do nosso corpo e não podemos produzi-las. (17) Assim, são fundamentais em todas as fases da vida, especialmente na infância, quando crescemos e nos desenvolvemos". (18) Já a trans, não satisfeita em não prestar para essas funções, ainda atrapalha as outras!

(19) Portanto, a Agência Nacional de Vigilância Sanitára (Anvisa) -parte do governo responsável por controlar essas questões - diz que é seguro para a saúde ingerir apenas menos de $2 \mathrm{~g}$ de gordura trans por dia. (20) Só que essa quantidade é tão pequena que apenas as refeições dariam conta, ou seja: não sobra quase nada para as guloseimas industrializadas! (21) E agora?!?

(22) 0 que podemos fazer, a partir de agora, é sempre olhar a tabelinha nas embalagens das comidas, que informa a quantidade (em gramas) dessa gordura. (23) Dê preferência às guloseimas que não tenham as trans, para forçar as indústrias a se preocuparem mais com a nossa saúde e mudarem seus ingredientes para outros mais saudáveis. (24) Você também pode fazer as contas: somar toda a quantidade de gordura trans que comeu no dia. (25) Se chegar à quantidade máxima, guarde o resto das guloseimas para o dia seguinte! (Verjovsky, 2007).

0 texto 'Trans... o quê?' explica por que se tornou obrigatória a discriminação dos tipos de gordura nos rótulos das embalagens. Os segmentos 3 a 8 correspondem ao satélite da relação de Solução e expressam um questionamento relacionado à área da química: por que se tornou obrigatória a discriminação dos tipos de gordura nos rótulos das embalagens? Os segmentos 9 a 18 equivalem ao núcleo da relação de Solução e apresentam as causas dessa obrigatoriedade: 
os malefícios da gordura transaturada. 0 texto 'Trans... o quê?' integra, dessa forma, a totalidade de 17 textos constituídos pela relação de Solução cujo núcleo apresenta as causas da questão exposta no satélite.

Desses 17, apresentam ocorrências de discurso relatado 11 textos, dentre os quais está o texto 'Trans... o quê?'. Afirmações da nutricionista Vera Lucia Chiara, pesquisadora da Universidade do Estado do Rio de Janeiro (UERJ), constituem os segmentos 14 a 17 do texto. Suas afirmações sobre o acúmulo da gordura transaturada em nosso corpo ao longo dos anos, sobre a possibilidade de isso causar doenças no coração e nas artérias e sobre a importância do consumo das gorduras insaturadas fundamentam as asserções do produtor do texto (Verjovsky, 2007)sobre os malefícios da gordura transaturada, os quais equivalem às causas da obrigatoriedade da discriminação dos tipos de gordura nos rótulos das embalagens. Assim, as asserções de Vera Lucia Chiara se referem à resolução do problema expresso no satélite da relação de Solução, o que justifica que se insiram no núcleo dessa relação.

Quanto ao modo de denominação, a fonte é indicada por seu nome ('Vera Lucia Chiara'), por seu título ('nutricionista'), por sua função ('pesquisadora') e pela instituição a que se vincula ('Universidade do Estado do Rio de Janeiro’). Em relação à modalidade de enunciação, o produtor tanto integra uma afirmação da fonte a seu texto, como em "A nutricionista Vera Lucia Chiara, que estuda o assunto na Universidade do Estado do Rio de Janeiro (UERJ), contou à CHC On-line que essa gordura vai se acumulando em nosso corpo ao longo dos anos e pode causar doenças no coração e nas artérias", mediante o emprego do verbo "contar", quanto procede a uma citação, como em “"Elas são essenciais porque participam de algumas funções do nosso corpo e não podemos produzi-las. Assim, são fundamentais em todas as fases da vida, especialmente na infância, quando crescemos e nos desenvolvemos'”, mediante a reprodução fiel do discurso de origem.

Além disso, uma asserção proveniente da Agência Nacional de Vigilância Sanitária (Anvisa) se localiza no segmento 19 do texto. Essa fonte recomenda a ingestão máxima diária de 2 gramas de gordura transaturada. Esta informação, no entanto, não mais explica a causa da obrigatoriedade da discriminação dos tipos de gordura nos rótulos da embalagem -finalidade do texto que constitui os segmentos da relação de Solução- mas corresponde a uma informação referente a uma perspectiva não explicitada no texto -a quantidade de gordura transaturada a ser consumida-, o que determina que essa ocorrência de discurso relatado se insira em um segmento da relação de Comentário. 0 modo de denominação, neste caso, equivale à indicação do nome de uma instituição -Agência Nacional de Vigilância Sanitária (Anvisa)-, e a modalidade de enunciação corresponde à integração do discurso de origem no discurso relatado, na qual se emprega o verbo ‘dizer’. 
São frequentes, também, as ocorrências de discurso relatado nos textos em que se descrevem ações referentes ao problema expresso. Leia-se o seguinte texto:

\section{Exemplo 7}

(1) Cérebro

(2) 0 cérebro é um grande comandante: é ele quem dá as ordens para que nosso corpo funcione. (3) Mas os cientistas ainda não entendem exatamente como isso acontece.

(4) Os mais novos estudos dizem que os cheiros, as imagens, os sons, os gostos e as sensações da pele vão para a parte da frente de nosso cérebro, o córtex frontal. (5) Então, desse ponto, as informações são passadas de neurônio para neurônio até outras partes da cabeça, cada uma em seu lugar.

(6) Um neurônio pode se comunicar com outros 100 mil! (7) A inteligência, para os cientistas, é a nossa capacidade de juntar, cruzar e buscar no cérebro, no momento certo, todas as informações de que precisamos (Cérebro, 2008).

Neste texto, os segmentos 1 a 3, que constituem o satélite da relação de Solução, expressam uma questão: “como o cérebro comanda o corpo humano?”. Os segmentos 4 e 5 , que integram o núcleo da relação de Solução, respondem à pergunta mediante a descrição de uma ação: o processo de transmissão das informações entre o corpo humano e o cérebro. Dessa forma, o texto 'Cérebro' integra o conjunto de 13 textos de divulgação científica midiática formados pela relação de Solução em que o núcleo apresenta uma descrição de ação. Em 6 desses 13 textos, há ocorrências de discurso relatado, ou seja, aproximadamente $46 \%$ dos textos que descrevem uma ação para responder a uma questão apresentam discurso relatado.

O segmento 4 do texto 'Cérebro' apresenta uma ocorrência de discurso relatado: "Os mais novos estudos dizem que os cheiros, as imagens, os sons, os gostos e as sensações da pele vão para a parte da frente de nosso cérebro, o córtex frontal". O discurso relatado, neste caso, descreve a primeira etapa do processo de transmissão das informações entre o corpo humano e o cérebro -o envio ao córtex frontal das informações referentes aos cheiros, às imagens, aos sons, aos gostos e às sensações. A fonte é denominada de forma vaga ('os mais novos estudos'), uma vez que o produtor do texto não especifica os estudos -ou os responsáveis pelos estudosque descrevem esse processo. Além disso, integra-se, mediante o emprego do verbo "dizer", o discurso de origem ao texto, já que não há a reprodução fiel das asserções da fonte.

O texto 'Cérebro', dessa forma, exemplifica os textos em que o núcleo da relação de Solução, a fim de resolver um problema expresso no satélite, descreve uma ação. Além disso, ilustra o funcionamento do discurso relatado nos textos constituídos por uma descrição de ação: neste caso, a asserção da fonte descreve uma parte do processo descrito nos segmentos da Solução. 0 
discurso relatado fundamenta, dessa forma, as asserções do produtor dos textos de divulgação científica midiática constituídos pela relação de Solução, os quais visam responder a questões vinculadas a determinadas áreas do conhecimento científico.

\section{CONCLUSÕES}

A divulgação científica, que corresponde à transmissão dos conhecimentos da ciência à sociedade em geral, garante a participação ativa do cidadão no processo de expansão da ciência e da tecnologia. A mídia -impressa, radiofônica ou televisiva- pode proceder à divulgação da ciência. O projeto DCEROT (Divulgação Científica: Estratégias Retóricas e Organização Textual) examina, quanto à sua organização macroestrutural, 62 textos de divulgação científica midiática dirigidos a jovens e publicados nas versões on line das revistas Ciência Hoje das Crianças, Mundo Estranho e Recreio e do caderno Folhinha, do jornal Folha de São Paulo.

Dentre os textos que integram o corpus, 36 são constituídos pela relação de Solução, em que o núcleo apresenta uma resolução para um problema expresso no satélite referente a uma área do conhecimento científico. Quanto às informações expressas pelo núcleo da relação de Solução, Becker e Giering (2008) afirmam que as explicações de uma questão correspondem à apresentação de causas, à descrição de ações, à apresentação de finalidades e ao relato de ações.

Este trabalho examinou o discurso relatado nos textos de divulgação científica midiática do corpus constituídos pela relação de Solução. 0 discurso relatado corresponde, de acordo com Charaudeau (1992, 2007, 2008), a um procedimento linguístico em que um locutor relata a um interlocutor, em um espaço e em um tempo específicos, o que um outro locutor disse a outro interlocutor em um espaço e em um tempo distintos. Dentre os 36 textos compostos pela relação de Solução, 19 apresentam ocorrências de discurso relatado. A análise destes textos revelou que,

- quanto aos segmentos macroestruturais de localização do discurso relatado, em 12 textos, há discurso relatado na relação de Solução; em 7, na de Comentário; em 1, na de Circunstância; em 1, na de Elaboração; e, em 1, na de Preparação;

- quanto aos modos de denominação das fontes do discurso de origem, o produtor do texto as designa mediante a indicação de seu nome (associado ou não a seu título), de sua função ou de uma denominação vaga;

- quanto às formas do relato do discurso de origem, o produtor do texto procede à sua reprodução fiel ou à sua integração ao texto; 
- quanto às modalidades de enunciação, empregam-se verbos, como 'dizer', 'afirmar', 'contar' e 'lembrar-se', e expressões, como 'segundo' e 'de acordo com';

- quanto às informações expressas pelo núcleo da relação de Solução, dos 19 textos que apresentam ocorrências de discurso relatado, 11 explicam as causas de um problema, 6 descrevem ações relacionadas a uma pergunta, 1 apresenta as finalidades de uma questão, e 1 relata acontecimentos referentes ao problema.

O conteúdo do discurso relatado relaciona-se ao conteúdo dos segmentos macroestruturais em que se insere. Assim, uma ocorrência de discurso relatado em segmentos da relação de Solução refere-se à explicação de um problema, enquanto uma ocorrência de discurso relatado em segmentos da relação de Comentário expressa uma informação não diretamente relacionada à resposta a uma pergunta. No entanto, independentemente do conteúdo do núcleo da relação de Solução, o discurso relatado fundamenta a explicação do produtor do texto: quer se apresentem as causas de um problema, quer se descrevam ações, por exemplo, o discurso relatado sustentará a explicação, seja mediante a pormenorização de causas, seja mediante a descrição complementar de ações. Dessa forma, emprega-se o discurso relatado -apesar de suas distintas possibilidades de ocorrência conforme os segmentos macroestruturais e apesar de suas diferentes configurações linguísticas- a fim de assegurar a autenticidade e a legitimidade das asserções do produtor do texto.

\section{REFERÊNCIAS BIBLIOGRÁFICAS}

Becker, J. \& Giering, M. (2008). A relação de solução em textos de divulgação científica para jovens. II Colóquio da ALED no Brasil: Intercâmbio de Práticas Inovadoras, Brasília, Submissão.

Bernárdez, E. (1995). Teoría y epistemología del texto. Madrid: Cátedra.

Cérebro (2008). Recreio [em línea]. Disponível em: http://recreionline.abril.com.br/fique_ dentro/ciencia/corpohumano/conteudo_49542.shtml

Charaudeau, P. (1992). Grammaire du sens et de l'expression. Paris: Hachette.

Charaudeau, P. (2007). Discurso das mídias. São Paulo: Contexto.

Charaudeau, P. (2008). Linguagem e discurso: Modos de organização. São Paulo: Contexto.

Gonçalves, D. M. (2007). Estrelas não caem! Ciência Hoje das Crianças. Disponível em: http:// cienciahoje.uol.com.br/controlPanel/materia/view/967

Iwakura, M. (2007). Brrrrr! O frio chegou. Folhinha [em línea]. Disponível em: http://www1. folha.uol.com.br/folhinha/dicas/di17060605.htm 
Joly, L. \& Bittencourt, C. (2008). Como se forma a voz? Mundo Estranho [em línea]. Disponível em: http://mundoestranho.abril.com.br/materia/materia_254088.shtml

Mann, W. C. \& Thompson, S. A. (1988). Rhetorical Structure Theory: Toward a functional theory of text organization. Text, 8(3), 243-281.

Mizuta, E. (2008). Os continentes continuam se movimentando? Mundo Estranho [em línea]. Disponível em: http://mundoestranho.abril.com.br/materia/materia_204379.shtml

Vasconcelos, Y. \& Moreira, M. (2008). Existe alguma raça de cachorro que não late? Mundo Estranho [em línea]. Disponível em: http://mundoestranho.abril.com.br/materia/ materia_223582.shtml.shtml

Verjovsky, M. (2007). Trans... o quê? Ciência Hoje das Crianças [em línea]. Disponível em: http://cienciahoje.uol.com.br/controlPanel/materia/view/60617

\section{NOTAS}

1 Considera-se a relação de Preparação da seguinte forma:

\section{"PREPARAÇÃOO}

$\mathrm{N}$ : afirmação que vai ser apresentada.

S: informação preparando L para antecipar e interpretar a afirmação em $\mathrm{N}$.

Condição em $\mathrm{N}$ ou $\mathrm{S}$ individualmente: nenhuma.

Condições na combinação $\mathrm{N}+\mathrm{S}$ : $\mathrm{S}$ precede $\mathrm{N}$ no texto. $\mathrm{S}$ faz com que o Leitor se sinta mais preparado, interessado ou orientado para ler $\mathrm{N}$.

Efeito: o Leitor se sente mais preparado, interessado ou orientado para ler $\mathrm{N}$.

Locus do efeito: N" (Mann \& Thompson, 1988. Tradução do grupo de pesquisa DCEROT).

2 A relação de Comentário é considerada da seguinte forma:

\section{“COMENTÁRIO}

Definição: em uma relação de comentário, o satélite constitui uma nota subjetiva sobre um segmento anterior do texto. Não é uma avaliação ou interpretação. 0 comentário é geralmente apresentado sob uma perspectiva que não a que se encontra explicitada nos elementos focados no núcleo.

$\mathrm{N}$ : uma situação

S: constitui uma nota/observação subjetiva sobre um segmento anterior do texto

Condições na combinação $\mathrm{N}+\mathrm{S}$ : $\mathrm{S}$ refere-se a $\mathrm{N}$ expressando uma observação subjetiva numa perspectiva que não se encontra explicitada nos elementos focados no núcleo.

Efeito: L reconhece que a nota/observação apresentada em $S$ expressa uma informação subjetiva numa perspectiva que não a explicitada em $\mathrm{N}$

Locus do Efeito: N e S" (Mann \& Thompson, 1988. Tradução do grupo de pesquisa DCEROT). 